\title{
Clinical Outcome of Systemic Treatment for Advanced Soft Tissue Sarcoma: Real-Life Perspective in Japan
}

This article was published in the following Dove Press journal:

Drug Design, Development and Therapy

\section{Tomoki Nakamura (D) \\ Kunihiro Asanuma (D) \\ Tomohito Hagi (D) \\ Akihiro Sudo}

Department of Orthopaedic Surgery, Mie University Graduate School of Medicine, Tsu, Japan
Correspondence: Tomoki Nakamura Department of Orthopaedic Surgery, Mie University Graduate School of Medicine, Tsu, Mie, Japan

Tel +8I-5923I5022

Fax +8I-5923I52II

Email tomoki66@clin.medic.mie-u.ac.jp
Introduction: The median survival time of patients with advanced soft tissue sarcoma (STS) is typically $<12$ months. Since 2012 , physicians were able to administer second- and/ or third-line treatment easily in Japan, following the approval of new drugs, namely, pazopanib, eribulin, and trabectedin. We investigated the real-life experience of adults with advanced STS who received systemic therapy after the approval of the aforementioned new drugs.

Patients and Methods: We retrospectively evaluated 34 patients (median age: 66 years) with primary STS arising at the extremities/trunk or unresectable local and/or metastatic STS between 2012 and 2019. We evaluated the tumor response and patient survival after initial systemic treatment.

Results: As first-line treatment, doxorubicin and ifosfamide and other drugs were administered to 7 and 27 patients, respectively. Of 31 patients with an evaluable tumor response, partial response was observed in $2(6.5 \%)$ patients, and $16(52 \%)$ patients showed stable disease at 8 weeks. The 1 - and 2 -year survival rates were $51.4 \%$ and $28.4 \%$, respectively. The median overall survival (OS) time was 12.6 months. Tumor response to first-line therapy was related to patient prognosis.

Conclusion: New drugs may be beneficial for patients with advanced STS. When patients cannot receive anthracycline-based chemotherapy because of a high risk of side effects, we believe that the aforementioned drugs may be administered as the first-line treatment.

Keywords: soft tissue sarcoma, eribulin, pazopanib, trabectedin, efficacy, overall survival

\section{Introduction}

Soft tissue sarcomas (STSs) are rare and heterogeneous, including more than 50 histological types. ${ }^{1}$ Approximately $5-30 \%$ of the patients with STS experience local recurrences and $10-38 \%$ present clinically detectable metastases. ${ }^{2-5}$ The outcome for metastatic patients remains poor, with a median reported overall survival of 14-20 months; however, in clinical trials, the patient's condition was relatively stable because inclusion criteria, such as age and performance status (PS), were strictly regulated. $^{6-8}$ Adult STSs with spindle-shaped cells, despite their heterogeneity and acknowledged clinical, pathological, and molecular differences, are generally treated in a similar manner. Patients receiving systematic chemotherapy for widely metastatic or locally advanced diseases are not suitable for surgery or radiotherapy. In Japan, doxorubicin and ifosfamide were only approved for patients with STS before 2012. Recently, a Phase III trial that evaluated the effectiveness of 
trabectedin and pazopanib compared with that of dacarbazine and a placebo, respectively, reported a longer median progression-free survival (PFS) with trabectedin and pazopanib. ${ }^{9,10}$ Furthermore, a randomised phase III study conducted on 452 patients with leiomyosarcoma (LMS) and liposarcoma (LPS) for evaluating the efficacy of eribulin compared with that of dacarbazine reported a significant 2-month increase in the overall survival (OS) in the eribulin arm. ${ }^{9,11}$ Based on the findings of these clinical trials, pazopanib (since 2012), trabectedin (since 2015), and eribulin (since 2016) can be administered even to patients without a history of systemic doxorubicin-based chemotherapy and for any type of histology in Japan. Prolonged patient survival should be expected after the new era of administration of new drugs in Japan. In this study, we investigated the real-life experience of 34 Japanese adult patients with advanced STS who received systemic therapy after the approval of the new drugs.

\section{Patients and Methods}

\section{Patients and Treatment}

We retrospectively evaluated 34 patients with advanced STS who received systemic therapy between 2012 and 2019. The inclusion criteria were (a) primary STS arising at the extremities/trunk and (b) unresectable local or/and metastatic STS. Of the 34 patients with STS, systemic therapy was administered for locally unresectable tumours $(\mathrm{n}=5)$, metastases $(\mathrm{n}=28)$, and both local tumours and metastases $(n=1)$. Generally, doxorubicin and ifosfamide (AI) are administered as first-line treatment worldwide if patients have not received AI treatment previously. The patients who received $\mathrm{AI}$ as neoadjuvant and adjuvant chemotherapy are not eligible for receiving doxorubicin again in the advanced disease setting, as administration of doxorubicin again may introduce bias with respect to tumor response to chemotherapy. For patients aged $>70$ years, we considered other treatments, such as gemcitabine and docetaxel (GD) and eribulin therapies, because of the risk of doxorubicin-induced heart failure. First, we did not choose pazopanib therapy for patients with dedifferentiated LPS. We finally selected the treatment according to the patient's daily activities because the administration method is different for each drug. For example, trabectedin should be administered for 24 hours in the hospital, while pazopanib can be orally administered. Five patients had previously undergone metastasectomy. The primary aim of this study was to evaluate the efficacy of systemic therapy for STS. This assessment was based on the OS and objective radiological responses to drugs. The results were evaluated as the best overall response using the Response Evaluation Criteria in Solid Tumors version 1.1. Stable disease (SD) was defined as lack of disease progression for $>8$ weeks. This was not evaluated at a fixed timepoint. This study was conducted in accordance with the guidelines of the Declaration of Helsinki of 1964. We obtained approval from the Institutional Review Board (IRB) at Mie University Hospital before commencing the present study, and the IRB waived the need of obtaining informed consent from the patients owing to the retrospective study design. All patient data accessed complied with the relevant data protection and privacy regulations.

\section{Statistical Analyses}

The clinicopathological factors were evaluated using the Mann-Whitney $U$-test (quantitative data) and $\chi^{2}$ test (qualitative data). The OS was defined as the time from the initial administration of the drug to the date of death or last follow-up examination. Survival curves were constructed using the Kaplan-Meier method. A univariate Cox model was used to compare the OS of patients. A multivariate analysis was performed using a Cox proportional hazards model. Significant factors identified in the univariate analysis were included as variables in the multivariate analysis. $\mathrm{P}<0.05$ indicated statistical significance. For all statistical analyses, the StatView version 5.0 software program was used.

\section{Results}

\section{Patients' Characteristics}

Table 1 shows the demographic and baseline characteristics of the patients. The median age was 66 (range: 36-85) years. Eleven patients had received systemic chemotherapy with doxorubicin for primary STS as neoadjuvant and adjuvant chemotherapy. One patient received systemic chemotherapy with doxorubicin for a lymphoma. The histological subtypes were grouped as L-sarcoma (LMS or LPS) and non-L-sarcoma. The L-sarcoma group comprised 18 patients, including those with dedifferentiated LMS $(\mathrm{n}=10)$ and LPS $(\mathrm{n}=8)$. The non-L-sarcoma group comprised 16 patients, including those with undifferentiated pleomorphic sarcoma (UPS; $\mathrm{n}=7$ ), myxofibrosarcoma (MFS; $\mathrm{n}=4)$, synovial sarcoma $(\mathrm{n}=2)$, epithelioid sarcoma $(n=1)$, and extraskeletal osteosarcoma $(n=1)$. The median and mean follow-up durations 
Table I Patient's Characteristics

\begin{tabular}{|l|l|l|}
\hline Variables & & $\mathbf{n}$ \\
\hline Age & $>70$ years & 15 \\
& $<70$ years & 19 \\
\hline Sex & Male & 26 \\
& Female & 8 \\
\hline L-sarcoma & Yes & 18 \\
& No & 16 \\
\hline History of doxorubicin & Yes & 11 \\
Treatment & No & 23 \\
\hline Performance status & $0-1$ & 28 \\
& 2 & 6 \\
\hline
\end{tabular}

after the administration of the first-line treatment were 9.4 and 11.9 months, respectively.

\section{Tumor Responses}

As first-line treatment, eribulin $(n=15)$ was the most frequently used drug, followed by AI $(n=7)$, GD $(n=$ $6)$, pazopanib $(n=4)$, and trabectedin $(n=2)$. AI was used for 18 patients, including those who received AI as neoadjuvant and adjuvant chemotherapy. The patients who underwent AI treatment were significantly younger than those who did not (mean age: 61 years vs 70 years; $\mathrm{p}=$ 0.02). Among the 34 patients who constituted the study population, 31 had an evaluable tumor response (Table 2). Three patients were excluded because of treatment discontinuation owing to the development of drug-induced interstitial pneumonia and pneumothorax before the evaluation. Partial response (PR) was observed in $2(6.5 \%)$ patients with UPS $(n=1)$ and MFS $(n=1)$. The details are shown in Table 3. Of the 31 patients, $16(52 \%)$ patients showed SD at 8 weeks. Age ( $>70$ years vs $\leq 70$ years) and tumor histology (L-sarcoma vs non-L-sarcoma) were not related to tumor response.
Among patients in whom the first-line treatment was terminated, 18 patients received second-line therapy. As second-line treatment, eribulin $(n=7)$ was the most frequently used drug, followed by GD $(n=5)$, pazopanib $(n=$ 5) and trabectedin $(n=1)$. Among the 18 patients, 15 patients showed an evaluable tumor response (Table 2). Three patients were excluded because of treatment discontinuation owing to the development of drug-induced interstitial pneumonia and elevated serum liver enzyme level before the evaluation. PR was observed in 1 (6.7\%) patient with LMS who received eribulin treatment. Of the 15 patients with an evaluable tumor response, $5(33 \%)$ patients showed SD at 8 weeks.

Of the 18 patients, 7 patients received third-line treatment. PR was not observed. Of these 7 patients, 3 (43\%) patients showed SD +. received fourth- or fifth-line treatment.

\section{Survival}

At the final follow-up, 13 patients were alive with disease and the remaining 21 patients had died from their disease. Overall, the 1 - and 2-year survival rates were $51.4 \%$ and $28.4 \%$, respectively (Figure 1). The median OS time was 12.6 months. Tumor response to first-line therapy was related to patient prognosis. Patients with SD or PR had better OS than those with progressive disease (PD; $p=0.002)$. The median OS of patients with SD or PR and PD was 19.2 and 8 months, respectively (Figure 2). Table 4 shows the results of the log-rank analysis of the OS. Female patients had better OS than male patients $(\mathrm{p}=0.01)$. There was no significant difference in survival between patients aged $>70$ years and those aged $\leq 70$ years. The history of doxorubicin treatment was not predictive factor for survival. There was also no significant difference in survival between patients who received doxorubicin as first-line treatment and the other patients. In univariate analysis, PS (0-1 vs 2 ) and female sex were identified as significant prognostic factors for OS.

Table 2 The Response at First- and Second-Line Treatment

\begin{tabular}{|l|l|l|l|l|l|l|}
\hline \multirow{2}{*}{} & \multicolumn{2}{l|}{ First Line } & \multicolumn{2}{l|}{ Second Line } \\
\cline { 2 - 7 } & PR & SD & PD & PR & SD \\
\hline Al & & 3 & 4 & & \\
GD & 1 & 2 & 2 & & PD \\
Eribulin & 1 & 7 & 7 & 1 & 1 & 3 \\
Trabectedin & & 1 & & & 4 \\
Pazopanib & & 3 & & & 5 \\
\hline
\end{tabular}

Abbreviations: Al, doxorubicin and ifosfamide; GD, gemcitabine and docetaxel; PR, partial response; SD, stable disease; PD, progressive disease. 
Table 3 The Relationship Between Histology and First-Line Treatment

\begin{tabular}{|l|l|l|l|}
\hline & LPS & LMS & Others \\
\hline AI & $2(I)$ & $2(I)$ & $3(I)$ \\
GD & $2(I)$ & & I (I) \\
Eribulin & 4 & $3(2)$ & $8(6)$ \\
$\begin{array}{l}\text { Trabectedin } \\
\text { Pazopanib }\end{array}$ & & $2(2)$ & I (I) \\
\hline
\end{tabular}

Note: (): patients with partial response or stable disease evaluation.

Abbreviations: Al, doxorubicin and ifosfamide; GD, gemcitabine and docetaxel; LPS, liposarcoma; LMS, leiomyosarcoma.

In multivariate analysis, tumor response was a significant factor (Table 5).

\section{Discussion}

In this study, we analyzed the efficacy of systemic treatment in 34 patients with advanced STS. In contrast to data from clinical trials, ${ }^{9-11}$ our retrospective data represent real-life patient experience in Japan. We included patients

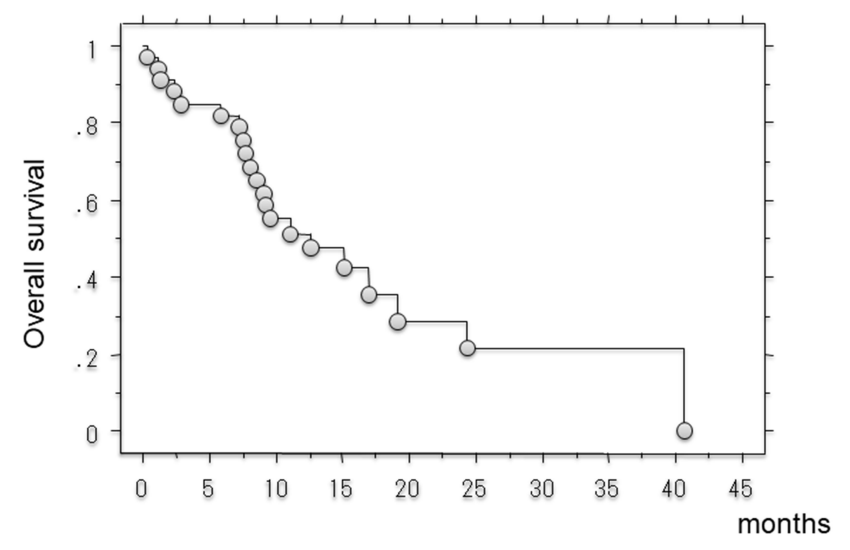

Figure I Kaplan-Meier curve showed post-treatment survival in all patients.

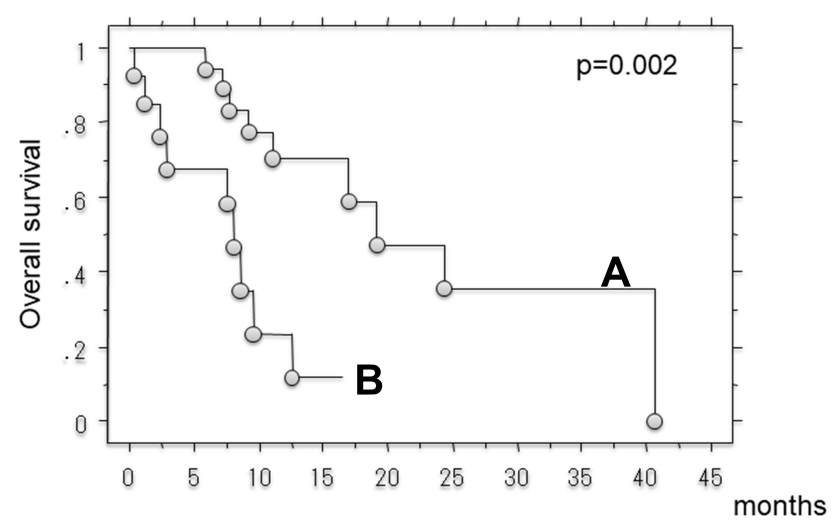

Figure 2 Kaplan-Meier curve showed post-treatment survival. (A: patients with PR or SD, B: patients with PD). of different ages presenting with varying PSs, history of doxorubicin therapy, and disease histology. The cohort included 15 patients who received pazopanib, eribulin, or trabectedin without a history of doxorubicin therapy, 15 patients aged $>70$ years, 6 patients with a PS score of 2 , and 17 patients with non-L-sarcoma. Age, history of doxorubicin therapy, and disease histology were not related to the treatment response and OS. PS was a prognostic factor for predicting OS in univariate analysis. Tumor response to first-line treatment was a prognostic factor for predicting the OS in multivariate analysis. The median OS time was 12.6 months. We previously evaluated patients who did not receive treatment for metastasis. ${ }^{12}$ The median post-metastatic survival of the 32 patients with advanced sarcoma was 7.2 months. Therefore, we consider that systemic therapy may be beneficial for patients with advanced STS. Since 2012, physicians were able to administer second- and/or third-line treatment easily owing to the approval of new drugs. These new drugs contribute to the maintenance of disease control after second-line treatment in $30-40 \%$ of the patients. However, in 2008, Karavasillis et al reported that the median posttreatment OS of 488 patients with advanced STS was 12 months. ${ }^{13}$ They did not use pazopanib, eribulin, or trabectedin. In their analysis, age $<40$ years was a positive independent prognostic factor. We did not include patients aged $<40$ years, except for 1 patient with LMS who was aged $<40$ years. Although age was not related to patient prognosis in the present study, Karavasillis et al described that the relative risk of death was 1.46 (95\% confidence interval: $1.10-1.92)$ in patients aged $>60$ years compared with that in patients aged $<40$ years. ${ }^{13}$ In the present study, the median patient age was 66 years. Therefore, we consider that new drugs (pazopanib, eribulin, and trabectedin) may be effective alternatives, especially for elderly patients, although additional studies are necessary to validate our findings.

In Japan, pazopanib, eribulin, and trabectedin can be administered even to patients without a history of previous systemic chemotherapy. Furthermore, GD is often administered to patients with advanced STS. However, anthracycline-based chemotherapy should be recommended because no regimen has proved to be unequivocally superior to doxorubicin as the first-line treatment for locally advanced or metastatic STS. ${ }^{14}$ When patients cannot receive anthracycline-based chemotherapy because of a high risk of side effects, we believe that the aforementioned drugs may be administered as the first-line 
Table 4 Prognostic Factors for Predicting Survival

\begin{tabular}{|c|c|c|c|c|c|}
\hline \multirow[t]{2}{*}{ Variables } & & \multirow[t]{2}{*}{$\mathbf{n}$} & \multicolumn{2}{|c|}{ Survival (\%) } & \multirow[t]{2}{*}{ p value } \\
\hline & & & I Year & 2 Years & \\
\hline Age & $\begin{array}{l}>70 \text { years } \\
<70 \text { years }\end{array}$ & $\begin{array}{l}15 \\
19\end{array}$ & $\begin{array}{l}60.9 \\
44.6\end{array}$ & $\begin{array}{l}20.3 \\
29.8\end{array}$ & 0.51 \\
\hline Sex & $\begin{array}{l}\text { Male } \\
\text { Female }\end{array}$ & $\begin{array}{l}26 \\
8\end{array}$ & $\begin{array}{l}83.3 \\
42.9\end{array}$ & $\begin{array}{l}83.3 \\
16.3\end{array}$ & 0.01 \\
\hline L-sarcoma & $\begin{array}{l}\text { Yes } \\
\text { No }\end{array}$ & $\begin{array}{l}18 \\
16\end{array}$ & $\begin{array}{l}63.9 \\
36.7\end{array}$ & $\begin{array}{l}28.4 \\
24.5\end{array}$ & 0.5 \\
\hline $\begin{array}{l}\text { History of } \\
\text { Doxorubicin tx }\end{array}$ & $\begin{array}{l}\text { Yes } \\
\text { No }\end{array}$ & $\begin{array}{l}18 \\
16\end{array}$ & $\begin{array}{l}48.7 \\
53.8\end{array}$ & $\begin{array}{l}24.4 \\
36.9\end{array}$ & 0.76 \\
\hline PS & $\begin{array}{l}0-1 \\
2\end{array}$ & $\begin{array}{l}28 \\
6\end{array}$ & $\begin{array}{l}57.8 \\
\text { NA }\end{array}$ & $\begin{array}{l}32 \\
\text { NA }\end{array}$ & 0.0002 \\
\hline Tumor & PR or SD & 18 & 70.6 & 47.1 & 0.002 \\
\hline Response & PD & 13 & 23.2 & NA & \\
\hline
\end{tabular}

Abbreviations: PR, partial response; SD, stable disease; PD, progressive disease; PS, performance status; NA, not available; tx, treatment.

Table 5 Multivariate Analysis for Predicting Survival

\begin{tabular}{|c|c|c|c|c|}
\hline Variables & & HR & $95 \% \mathrm{Cl}$ & $P$ value \\
\hline Sex & $\begin{array}{l}\text { Male } \\
\text { Female }\end{array}$ & $\begin{array}{l}1 \\
0.168\end{array}$ & $0.022-1.304$ & 0.09 \\
\hline PS & $\begin{array}{l}2 \\
0-1\end{array}$ & $\begin{array}{l}1 \\
0.374\end{array}$ & $0.077-1.807$ & 0.22 \\
\hline Tumor & PR or SD & I & & \\
\hline Response & PD & 3.545 & $|.067-||.77|$ & 0.04 \\
\hline
\end{tabular}

Abbreviations: PR, partial response; SD, stable disease; PD, progressive disease; PS, performance status; HR, hazard risk; $95 \% \mathrm{Cl}, 95 \%$ confidential interval.

treatment. However, when administering trabectedin and pazopanib, it is necessary to consider the risk of cardiac dysfunction. ${ }^{15}$

There are some limitations of this study. As this was a retrospective study, it may be difficult to directly compare it with previous studies, as the inclusion criteria with respect to tumor subtypes, eligibility, and follow-up procedures were different. Another limitation was the small size of the study population. The evaluation of trabectedin treatment was quite limited because patients with myxoid liposarcoma were not included. The choice of drugs used was decided by each physician. However, we believe that our study reflects the real-life experience of patients with advanced STS in Japan.

In conclusion, pazopanib, eribulin, and trabectedin may be beneficial for patients with advanced STS, although additional studies should be conducted to elucidate the efficacy of these drugs in younger patients.

\section{Ethics Approval}

This study was approved by the institutional review board of Mie University Hospital.

\section{Funding}

We did not receive any financial support for the completion of this study.

\section{Disclosure}

We declare that we have no conflict of interest to declare in relation to this study.

\section{References}

1. Clark MA, Fisher C, Judson I, et al. Soft-tissue sarcomas in adults. $N$ Engl J Med. 2005;353:701-711.

2. Zager GK, Ballo MT, Pesters PW, et al. Prognostic factors for patients with localized soft-tissue sarcoma treated with conservation surgery and radiation therapy; an analysis of 1225 patients. Cancer. 2003;97 (10):2530-2543. doi:10.1002/cncr.11365

3. Weiss SW, Goldblum JR. Local Recurrence. In: Enzinger and Weiss's Soft Tissue Tumors. 4th ed. St. Louis: Mosby; 2001:28-32.

4. Kane JM, Finley JW, Driscoll D, et al. The treatment and outcome of patients with soft tissue sarcomas and synchronous metastases. Sarcoma. 2002;6(2):69-73. doi:10.1080/1357714021000022168

5. Pollock RE, Karnell LH, Menck HR, et al. The national cancer data base report on soft tissue sarcoma. Cancer. 1996;78(10):2247-2257. doi:10.1002/(SICI)1097-0142(19961115)78:10<2247::AID-CNCR2 9>3.0.CO;2-Y 
6. Judson I, Verweij J, Gelderblom H, et al. Doxorubicin alone versus intensified doxorubicin plus ifosfamide for first-line treatment of advanced or metastatic soft-tissue sarcoma: a randomized controlled Phase 3 trial. Lancet Oncol. 2014;15(4):415-423. doi:10.1016/ S1470-2045(14)70063-4

7. Freeza AM, Stacchiotti S, Gronchi A. Systematic treatment in advanced soft tissue sarcoma: what is standard, what is new. $B M C$ Med. 2017;15(1):109. doi:10.1186/s12916-017-0872-y

8. Tap WD, Wagner AJ, Schoffski P, et al. Effect of doxorubicin plus olaratumab vs doxorubicin plus placebo on survival in patients with advanced soft tissue sarcomas: the ANNOUNCE randomized clinical trial. JAMA. 2020;323(13):1266-1276. doi:10.1001/jama.2020.1707

9. Demetri GD, von Mehren M, Jones RL, et al. Efficacy and safety of trabectedin or dacarbazine for metastatic liposarcoma or leiomyosarcoma after failure of conventional chemotherapy: results of a phase iii randomized multicenter clinical trial. J Clin Oncol. 2015;34 (8):786-793. doi:10.1200/JCO.2015.62.4734

10. van der Graaf WT, Blay JY, Chawla SP, et al. Pazopanib for metastatic soft-tissue sarcoma (PALETTE): a randomized, double-blind, placebo-controlled phase 3 trial. Lancet. 2012;379(9829):1879-1886. doi:10.1016/S0140-6736(12)60651-5
11. Schoffski P, Chawla S, Maki RG, et al. Eribulin versus dacarbazine in previously treated patients with advanced liposarcoma or leiomyosarcoma: a randomised, open-label, multicenter, phase 3 trial. Lancet. 2016;387(10028):1629-1637. doi:10.1016/S0140-6736(15)01283-0

12. Nakamura T, Matsumine A, Matsubara T, Asanuma K, Uchida A, Sudo A. Retrospective analysis of metastatic sarcoma patients. Oncol Lett. 2011;2(2):315-318. doi:10.3892/ol.2011.238

13. Karavasilis V, Seddon BM, Ashley S, Al-Muderis O, Fisher C, Judson I. Significant clinical benefit of fist-line palliative chemotherapy in advanced soft-tissue sarcoma. Cancer. 2008;112(7):15851591. doi:10.1002/encr. 23332

14. Seddon B, Strauss SJ, Whelan J, et al. Gemcitabine and docetaxel versus doxorubicin as first-line treatment in previously untreated advanced unresectable or metastatic soft-tissue sarcomas (GeDDiS): a randomised controlled phase 3 trial. Lancet Oncol. 2017;18 (10):1397-1410. doi:10.1016/S1470-2045(17)30622-8

15. Kawai A, Yonemori K, Takahashi S, Araki N, Ueda T. Systemic therapy for soft tissue sarcoma: proposal for the optimal use of pazopanib, trabectedin and eribulin. Adv Ther. 2017;34(7):15561571. doi:10.1007/s12325-017-0561-4

\section{Publish your work in this journal}

Drug Design, Development and Therapy is an international, peerreviewed open-access journal that spans the spectrum of drug design and development through to clinical applications. Clinical outcomes, patient safety, and programs for the development and effective, safe, and sustained use of medicines are a feature of the journal, which has also been accepted for indexing on PubMed Central. The manuscript management system is completely online and includes a very quick and fair peer-review system, which is all easy to use. Visit http://www. dovepress.com/testimonials.php to read real quotes from published authors. 